\title{
Un nuevo enfoque sobre la cultura y la literatura del medio siglo a través del estudio de la literatura del yo
}

\section{A New Approach to Gulture and Literature of the Second Half of the $2^{\text {th }}$ Century through the Analysis of Self- \\ Literature}

Adrián Ramírez Riaño

Universidad Complutense de Madrid (Madrid)

adrami02@ucm.es

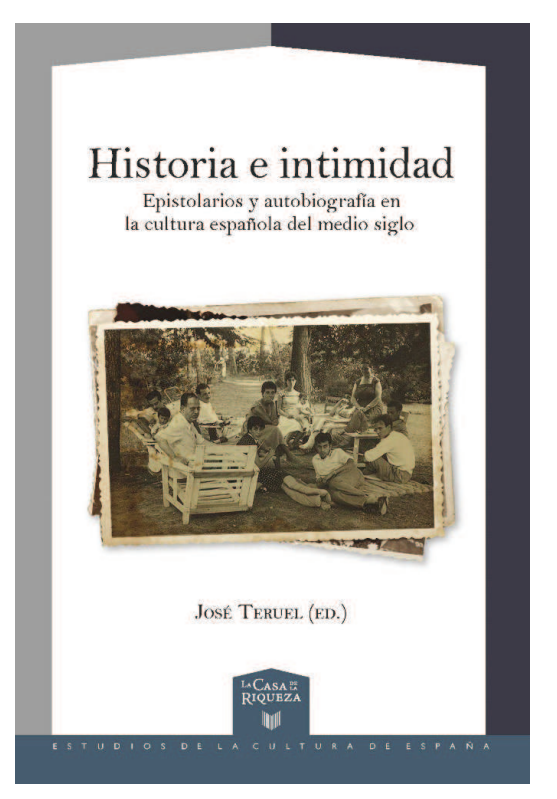

Reseña de la obra/ Book Review: Teruel, José (ed.) (2018). Historia e intimidad: epistolarios y autobiografía en la cultura española del medio siglo. Madrid [et al.]: Iberoamericana-Vervuert, 296 p. ISBN 978-84-16922-51-2

El presente libro aboga por el interés que merecen un conjunto de textos al que no siempre la crítica ha prestado la debida atención. Este volumen colectivo que ha coordinado el profesor José Teruel trata de demostrar el hecho de que los epistolarios, las autobiografías, los cuadernos íntimos y los diarios -es decir, los textos que conforman la literatura del yo- son también parte del canon literario y deben entenderse como parte de la obra artística de sus autores. Desde la óptica histórica y cultural, la crítica literaria debe abordar los caminos del yo biográfico en los textos personales de los grandes autores (en este caso del medio siglo español) para encontrar en ellos variantes interpretativas de su situación artística, cultural, histórica y personal. Este volumen está formado por dieciséis capítulos en los que 
no solo se busca una interpretación del propio texto personal, sino que se realza su potencial de conocimiento respecto a la producción de los autores. Por lo tanto, el estudio de los géneros del yo sirve para entender la historia literaria y para valorar la función de estos géneros en la propia construcción de la identidad de sus autores. Al final de la lectura, queda clara una conclusión fundamental: sin la literatura del yo no se podría comprender la cultura del medio siglo.

El libro comienza con un estudio de José Teruel, coordinador del colectivo e investigador principal del proyecto Epistolarios, memorias, diarios, y otros géneros autobiográficos de la cultura española de medio siglo, y de Ana Garriga Espino, donde trazan, a manera de introducción, un relato teórico-crítico para comprender el valor genérico de los epistolarios y los textos de las escrituras del yo. Ambos advierten de la de la dificultad pero también de la necesitad, especialmente en el género epistolar, de traspasar el ámbito de los destinatarios explícitos. Como afirman en este capítulo, los epistolarios nos sirven, sin ser los críticos unos espías de la intimidad del autor, para asimilar mejor la literatura a través de las meditaciones de sus autores. Los epistolarios, ante la muerte del autor barthesiana, se encuentran en lo que "parece fraguarse en la tierra de nadie que separa esa distancia aparentemente insalvable entre vida y obra, que clamaba un importante sector de la crítica literaria" (18). Pero es ese punto intermedio el que confiere a la carta la capacidad de ser género literario. Además, nos recuerdan, que es el género epistolar el molde de la novela moderna con el Lazarillo de Tormes. Por lo tanto, el género epistolar se convierte en un motor de relatos en los que la mayor aproximación personal o la menor implicación autorial son indiferentes. A lo largo de la introducción se pretende recalcar el valor literario de la epistolografía y, sobre todo, el valor real de significación del lector y del editor que, a lo largo de los silencios y de la intimidad de los escritores, incrementa el poder interpretativo en la decodificación de las propias cartas desde dos puntos de vista: el de la construcción de la carta en sí misma y el de la relación de lo dicho en ellas con el resto de la obra y la cultura histórica del autor. Junto con ello se hace especial hincapié en la abundancia de estudios y ediciones sobre epistolografía en la Edad de Plata frente a la del medio siglo, por la "parvedad de correspondencias publicadas de este generación" (24). Por lo tanto, el presente volumen se predispone como el primer estudio completo de la literatura del yo del medio siglo esperando un mayor interés de la misma en el mundo investigador.

Para llegar a una mejor praxis académica, Julio Neira, en su texto "La correspondencia de Caballero Bonald: propuesta metodológica para una historia epistolar de medio siglo" expone unos puntos indispensables para trabajar de modo eficaz los epistolarios de una época, que frente a la Edad de Plata, como hemos advertido, ha sido escasamente estudiada. Por consiguiente, recalca el valor documental de los epistolarios, diarios personales y autobiografías para comprender el proceso creativo, el contexto sociológico-histórico y el proceso de edición (115118). Esta es la razón de la creación de una serie de archivos y de fundaciones, además de proyectos, cuyo motivo es preservar el archivo epistolar y ofrecer al 
estudioso la capacidad y la facilidad de realizar un estudio detallado. Como ejemplo de las razones teóricas expuestas, Julio Neira presenta el epistolario de Caballero Bonald en el que estudia las relaciones del escritor jerezano con otros poetas de su generación: los viajes, los ideales estéticos, los proyectos conjuntos...etc.

A propósito de esto, al ser el medio siglo una época poco analizada desde los parámetros de la escritura del yo, el naciente aproximamiento cumple varias funciones. En primer lugar, para comprender el valor de las influencias de un autor en otro en sus obras literarias: es el caso de Américo Castro y Juan Goytisolo. Santiago LópezRíos en su artículo "La génesis de Reivindicación del conde don Julián a la luz de la correspondencia Américo Castro-Juan Goytisolo" nos presenta la génesis de la obra del barcelonés a través de sus textos epistolares. En la correspondencia se entrevé la relación de amistad y de afecto, y la personalidad de ambas figuras y sus relaciones intelectuales en común (Juan Goytisolo llegó incluso a proponerle a Américo Castro dedicarle Don Julián). De la misma manera Sergio García García en "La amistad de Claudio Rodríguez y José Agustín Goytisolo a través de su correspondencia" explica cuál era la relación afectiva entre ambos poetas para comprender mejor cómo Claudio Rodríguez conoció al elitista grupo de Barcelona, gracias a su conexión con José Agustín Goytisolo. Pero las misivas no solo sirven para comprender los lazos de amistad y de intereses literarios. Por ejemplo, Andrea Toribio Álvarez, en su artículo, se dedica a estudiar la relación de amistad entre Carmen Marín Gaite y Esther Tusquets. En él recalca que es de vital importancia comprender su relación editorial, puesto que la segunda fue editora de la primera. Así podemos conocer de primera mano los planteamientos editoriales de la escritora y el modus operandi de la editora. La correspondencia, además, nos sirve para conocer mejor los avatares de un artista y la relación de este con el resto. Es el caso de Labordeta y Ory: José Antonio Llera analiza la relación de los dos poetas en sus epistolarios. Gracias a estos textos podemos saber que Ory le aconseja a Labordeta no publicar un poema en concreto y su compañero, haciéndole caso, lo deja sin publicar. Por su parte, Carmen de la Guardia se lamenta de la falta de estudio de epistolarios inéditos entre escritoras. En su trabajo se expone principalmente el hecho de que la mujer escritora se inclina predominantemente más hacia la literatura del yo, y por ello debemos reparar en sus textos autobiográficos y en su correspondencia, ya que en ellas se tejen relaciones de amistad y de apoyo fraternal y literario. Aún quedan muchos epistolarios inéditos y es la labor de los filólogos editarlas y delimitar el conocimiento personal y literario de las grandes autoras en español, en este caso de medio siglo. Por último Pedro Álvarez de Miranda nos presenta una carta inédita de Dionisio Ridruejo en "Una carta de Dionisio Ridruejo (1952)" en donde el poeta cuenta a sus intermediarios sus recuerdos en Roma y su estado personal de trabajo. Gracias a la carta conocemos sus proyectos literarios e intelectuales y su situación vital e histórica.

Pero el corpus las escrituras del yo no solo se conforma de los epistolarios, también podemos adentrarnos en sus diarios y en sus cuadernos de notas. El mayor ejemplo es Jaime Gil de Biedma, cuyos diarios han sido publicados recientemente a 
los veinticinco años de su muerte. José Teruel en su artículo "Hacia una autobiografía de Jaime Gil de Biedma. La doble insuficiencia del arte y la vida" demuestra (y también a partir de su correspondencia) la diferencia entre intimidad y privacidad para comprender que el yo de los diarios de Gil de Biedma es una reflexión que luego pergeña en la escritura del enmascarado de sus poemarios. Es en esos diarios y cartas donde aparecen las obsesiones literarias y personales del autor que luego se ven reflejadas en su poesía y en sus ensayos. Gil de Biedma es el claro ejemplo de autor que reconstruye su propia vida gracias a la meditación poética de su personaje literario. Es en estos textos donde puede discernirse la autobiografía real y la creada por el sujeto de carne y hueso. En los diarios personales (pensados para ser publicados o no), el lector se encuentra las razones del comportamiento de los individuos y de las generaciones literarias. En ese sentido, José Luis Ortega conecta a dos grandes poetas y amigos (Gil de Biedma y Barral) mediante los diarios personales poéticos de Moralidades y Metropolitano donde se observan sus inquietudes y sus afinidades y las conexiones intelectuales de dos miembros de grupo y de generación. Pero los diarios también sirven para que comprendamos la forma de pensar y la manera de ser de los autores y cómo puede traslucirse en su obra literaria. En "La reconversión de los intelectuales falangistas a mediados de siglo: Gonzalo Torrente Ballester." José Lázaro argumenta las razones de su viraje ideológico desde la dictadura hacia los primeros años democráticos del autor gallego y de muchos otros compañeros intelectuales. Del mismo modo, Joana Sabadell-Nieto en "Hacer(se) público. Las preocupaciones diarias de Gonzalo Torrente Ballester" explica el valor de los diarios como expresión pública de lo personal ante la dureza de la censura de la dictadura franquista. Son los diarios y los epistolarios una vía libre de escritura y de creación personal y literaria ante las imposiciones ideológicas del mundo exterior.

La última modalidad genérica que se estudia es la autobiografía o las memorias. Celia Fernández Prieto en "Memorias de infancia y de guerra (sobre textos de Jacint y Joan Reventós, Antonio Rabinad y Jaime de Armiñán)." destaca desde distintos puntos de vista el modo de narrar la infancia de los llamados "hijos de la guerra". Desde otro punto de vista, Elisa Martín Ortega dedica su trabajo ("La memoria en la obra de Esther Tusquets: entre la intimidad y la crónica de una época”) a resaltar el detalle de que la obra de la catalana es, en mayor o menor medida, autobiográfica, y se centra en sus últimas obras de importante convencimiento biográfico e histórico. Es a partir de estos textos donde comprendemos mejor la personalidad literaria, editorial e individual que impregna toda su obra. Pero la autobiografía puede aparecer en textos que no parecen del todo memorias. Elide Pittarello estudia el valor autobiográfico en los diarios-collage de Carmen Martín Gaite en Nueva York. En ellos se aprecia cómo la autora española conoce la obra de Virginia Woolf (a quien traducirá) y cómo impregna su obra, además de su relación con la gran ciudad americana y sus quehaceres diarios. Finalmente, Maria Vittoria Calvi presenta un estudio muy particular, ya que explica las relaciones autobiográficas y artísticas de Carmen Martín Gaite en los paratextos escogidos para todas sus obras. Esta 
apreciación hace posible ver la importancia de los estudios de la literatura del yo para comprender las razones personales que interfieren en la creación literaria y en el significado de sus obras.

En resumen, ante el auge del estudio de la literatura epistolar y personal de la historia de la literatura española, este volumen presenta el estudio crítico-filológico de varios autores relacionados entre sí, pertenecientes a una generación y época poco estudiadas desde la vertiente de la epistolografía y las escrituras del yo: el medio siglo. Ante la dificultad teórica de trazar argumentos a favor y en contra de admitir como literatura a los epistolarios, los diarios y las memorias, el prisma del texto autobiográfico supone un nuevo acercamiento al autor y sus textos. Este volumen deja patente la conveniencia y la utilidad de abordar y analizar textos autobiográficos y corpus epistolográficos desde la dicotomía de lo externo-interno, es decir, de lo histórico-cultural y lo literario, como centro de pruebas de escritura de relatos y de la reescritura de uno mismo. 